\title{
Molecular characterization of Hymenolepis nana based on nuclear rDNA ITS2 gene marker
}

\author{
Mojtaba Shahnazi ${ }^{1,2}$, Majid Zarezadeh Mehrizi ${ }^{1,3}$, Safar Ali Alizadeh ${ }^{4}$, Peyman Heydarian $^{1,2}$, \\ Mehrzad Saraei ${ }^{1,2}$, Mahmood Alipour ${ }^{5}$, Elham Hajialilo ${ }^{1,2}$
}

1. Department of Parasitology, Qazvin University of Medical Sciences, Qazvin, Iran.

2. Cellular \& Molecular Research Center, Qazvin University of Medical Sciences, Qazvin, Iran.

3. Student Research Committee, Qazvin University of Medical Sciences, Qazvin, Iran.

4. Department of Microbiology, Qazvin University of Medical Sciences, Qazvin, Iran.

5. Department of Social Medicine, Qazvin University of Medical Sciences, Qazvin, Iran.

\begin{abstract}
Introduction: Hymenolepis nana is a zoonotic tapeworm with widespread distribution. The goal of the present study was to identify the parasite in the specimens collected from NorthWestern regions of Iran using PCR-sequencing method.

Methods: A total of 1521 stool samples were collected from the study individuals. Initially, the identification of hymenolepis nana was confirmed by parasitological method including direct wet-mount and formalin-ethyl acetate concentration methods. Afterward, PCR-sequencing analysis of ribosomal ITS2 fragment was targeted to investigate the molecular identification of the parasite.

Results: Overall, $0.65 \%(10 / 1521)$ of the isolates were contaminated with $H$. nana in formalin-ethyl acetate concentration. All ten isolates were succefully amplified by PCR and further sequenced. The determined sequences were deposited in GenBank under the accession numbers MH337810-MH337819.

Conclusion: Our results clarified the presence of H. nana among the patients in the study areas. In addition, the molecular technique could be accessible when the human eggs are the only sources available to identify and diagnose the parasite.

Keywords: Hymenolepis nana, rDNAITS2, PCR, Iran.

DOI: https://dx.doi.org/10.4314/ahs.v19i1.6

Cite as: Shabnazi M, Mehrizi MZ, Alizadeh SA, Heydarian P, Saraei M, Alipour M, Hajialilo E. Molecular characterization of Hymenolepis nana (Cestoda: Cyclophyllidea: Hymenolepididae) based on nuclear rDNA ITS2 gene marker. Afri Health Sci. 2019;19(1): $1346-1352$. https:/ / dx.doi.org/10.4314/abs.v19i1.6
\end{abstract}

\section{Introduction}

Hymenolepis nana, generally known as the dwarf tapeworm, is one of the most common tapeworms of humans and rodents, in which the parasite can cause hymenolepiasis. This zoonotic tapeworm has a cosmopolitan distribution with socio-economic and medical significance which may occur in many countries, worldwide ${ }^{1,2}$. The parasite is among the neglected tropical diseases (NTD). Human

\section{Corresponding author:}

Elham Hajialilo, Department of Parasitology, Qazvin University of Medical Sciences, Qazvin, Iran

Email: e.hajialilo@qums.ac.ir hymenolepiasis caused by one of two adult tapeworms Hymenolepis diminuta or Hymenolepis nana, is a globally widespread zoonotic infection known to be endemic in Asia, Southern and Eastern Europe, Central and South America, and Africa ${ }^{3,45}$. H. nana, however, accounts for the most common cause of all cestode infections in humans and in temperate zones with high incidence in children and institutionalized groups ${ }^{6,7}$. Although the extent of clinical manifestations depends on the worm burden yet the infection with $H$. nana usually causes many clinical symptoms such as headache, weakness, anorexia, abdominal pain, and diarrhea ${ }^{8}$. Infection is usually self-cleared by adolescence and is infrequent in healthy adults ${ }^{7}$. The drug of choice to treat hymenolepiasis is praziquantel which is more effective than other drugs including mebendazole or niclosamide?

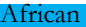

Health Sciences

(C) 2019 Shahnazi et al. Licensee African Health Sciences. This is an Open Access article distributed under the terms of the Creative commons Attribution License (https://creativecommons.org/licenses/BY/4.0), which permits unrestricted use, distribution, and reproduction in any medium, provided the original work is properly cited. 
H. nana is the only cestode capable of completing its life cycle in the final host without involving an intermediate host. It is also able to complete its entire cycle in a single host (auto-infection) ${ }^{10}$. The worm could be easily renewed by new generations and complete their life cycle only in human intestine. The issue may cause epidemics in close proximity and compact environments such as childcare institutions, dorms, and barracks ${ }^{11}$. Contamination is most commonly acquired from eggs in the faeces of another infected individual, transferred by contaminated food ${ }^{12}$, although an indirect life cycle utilizing insects as intermediate hosts may occur ${ }^{10}$. Expulsed eggs in human faeces have an important role in diagnosis as they are used to identify morphological features ${ }^{13}$. However, with advancement in the field of molecular biology, techniques such as polymerase chain reaction (PCR) has provided simple and rapid procedure in identification of parasites. This approach is a widely used method for the accurate differentiation and characterization of helminthic parasites including the cestodes ${ }^{14,17}$.

Up to now several studies have reported the presence of H.nana infection in Iran with prevalence rates ranging from $0.01 \%$ to $10 \%$ in different part of the country18-22, although these researches mainly focused on morphological method. Therefore, there was a need for a precise and sensitive method that could more accurately detect the parasite. So the main objective of the present study was to molecular characterization of $H$. nana in Qazvin province, North West of Iran.

\section{Materials and method}

\section{Sample collection and processing}

A total of 1521 stool samples were collected from the individuals, referred to Shahid Bolandian health care center in Qazvin province, situated in Northern border of central Iran, to be routinely examined for the presence of ova and parasites in 2016. Ethical approval of the study was obtained from the Medical Ethics Committee of Qazvin University of Medical Sciences (IR. QUMS. REG. 1396. 293). All specimens were surveyed in the parasitology laboratory at Qazvin Medical School. Diagnosis of $H$. nana was confirmed by direct wet-mount and formalin-ethyl acetate concentration methods.

\section{DNA extraction and PCR amplification}

Genomic DNA was extracted by QIAamp DNA Stool Mini Kit. (QIAGEN, Germany). The internal transcribed spacer 2 (ITS2) region of ribosomal DNA (rDNA), was amplified using specific primers of $H$. nana as follows: Forward primer (ITS2F): 5' GTGAATCGCAGACTGCT'T'TG 3'

\section{Reverse Primer (ITS2R): 5' CTGAGGTCAG- GTCTTCCATAC 3'}

Twenty microliter reaction volume containing a readymade mixture of Amplicon (Taq DNA Polymerase Master Mix RED, Denmark) with template DNA, $0.1 \mu \mathrm{M}$ of each primer and distilled water were used for PCR under following temperature conditions: $95{ }^{\circ} \mathrm{C}$ for $5 \mathrm{~min} ; 35$ cycles of $95{ }^{\circ} \mathrm{C}$ for $20 \mathrm{~s}$, annealing step at $59{ }^{\circ} \mathrm{C}$ for 20 $\mathrm{s}$ and $72{ }^{\circ} \mathrm{C}$ for $30 \mathrm{~s}$; final extension cycle of $72{ }^{\circ} \mathrm{C}$ for 5 min. Subsequently, the PCR product was stained and electrophoresed on a $\%$ agarose gel in TBE buffer (Tris, boric acid and EDTA). The specific band appeared under UV light.

\section{Sequencing analysis}

All PCR products were purified and sequenced with ABI $3130 \mathrm{X}$ sequencer. The resulting sequences were adjusted manually by chromas (version 1.0.0.1), and then compared with available reference sequences in BLAST GenBank database by BLAST software available at (https:/ / blast.ncbi.nlm.nih.gov/Blast.cgi). All H. nana sequences were submitted to the NCBI database under the Accession Nos. MH337810- MH337819.

\section{Phylogenetic analysis}

ClustalW incorporated in the BioEdit software was used to sequence alignment (Hall1999). Phylogenetic tree was constructed by the MEGA7 software (Molecular and Evolution Genetic Analysis v6), Maximum-Likelihood algorithm with Tamura-3 parameter substitution model was applied. Finally, a bootstrap number of 1000 replicates was considered.

\section{Statistical method}

Chi-square test using SPSS software version 17.00 (SPSS Inc., Chicago, IL, USA) was used to determine signification of variables. A P value of $<0.05$ was considered significant for differences, statistically.

\section{Results}

Out of 1521 stool samples, $10(0.65 \%)$ isolates were contaminated with $H$. nana in formalin-ethyl acetate concentration (Fig. 1). 


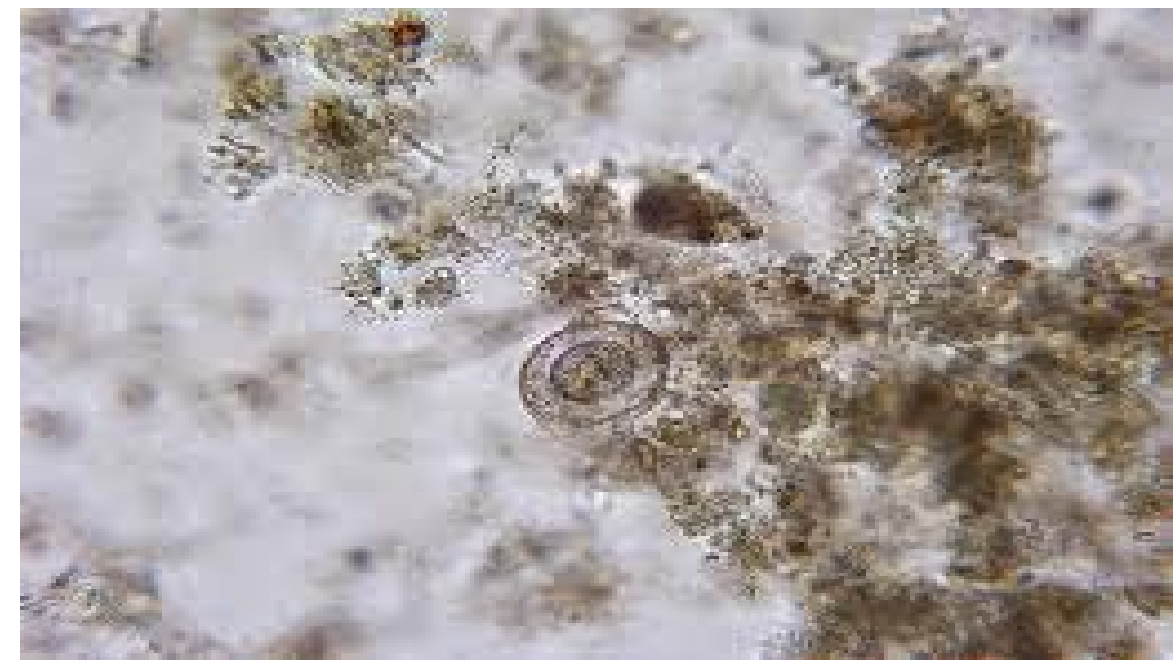

Figure1: The egg of H.nana in stool examination with $\times 400$ magnifications (These pictures were originally captured from the current study specimens.)

PCR-amplification of the rDNA ITS2 region yielded a

single band of approximately $530 \mathrm{bp}$ for $H$. nana (GenBank accession number MH337810 -MH337819) (Fig. 2).

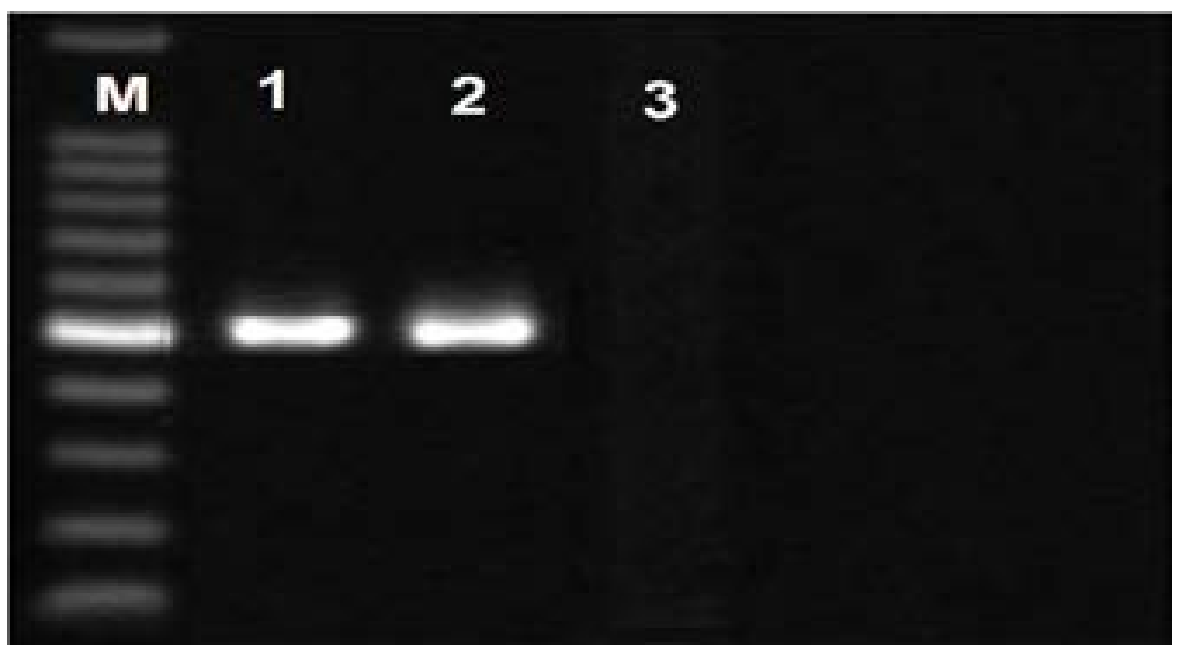

Figure2: PCR patterns of H.nana obtained from patient's samples. Lane M 100-bp size marker, Lane 1 and 2 H.nana (530 bp), Lane 3 Negative control

To determine the inter-relationship between $H$. nana and their taxonomic correlation and other members of the family Hymenolepididae, phylogenetic trees were constructed taking Taenia hydatigena as the outgroup (Fig. 3). 


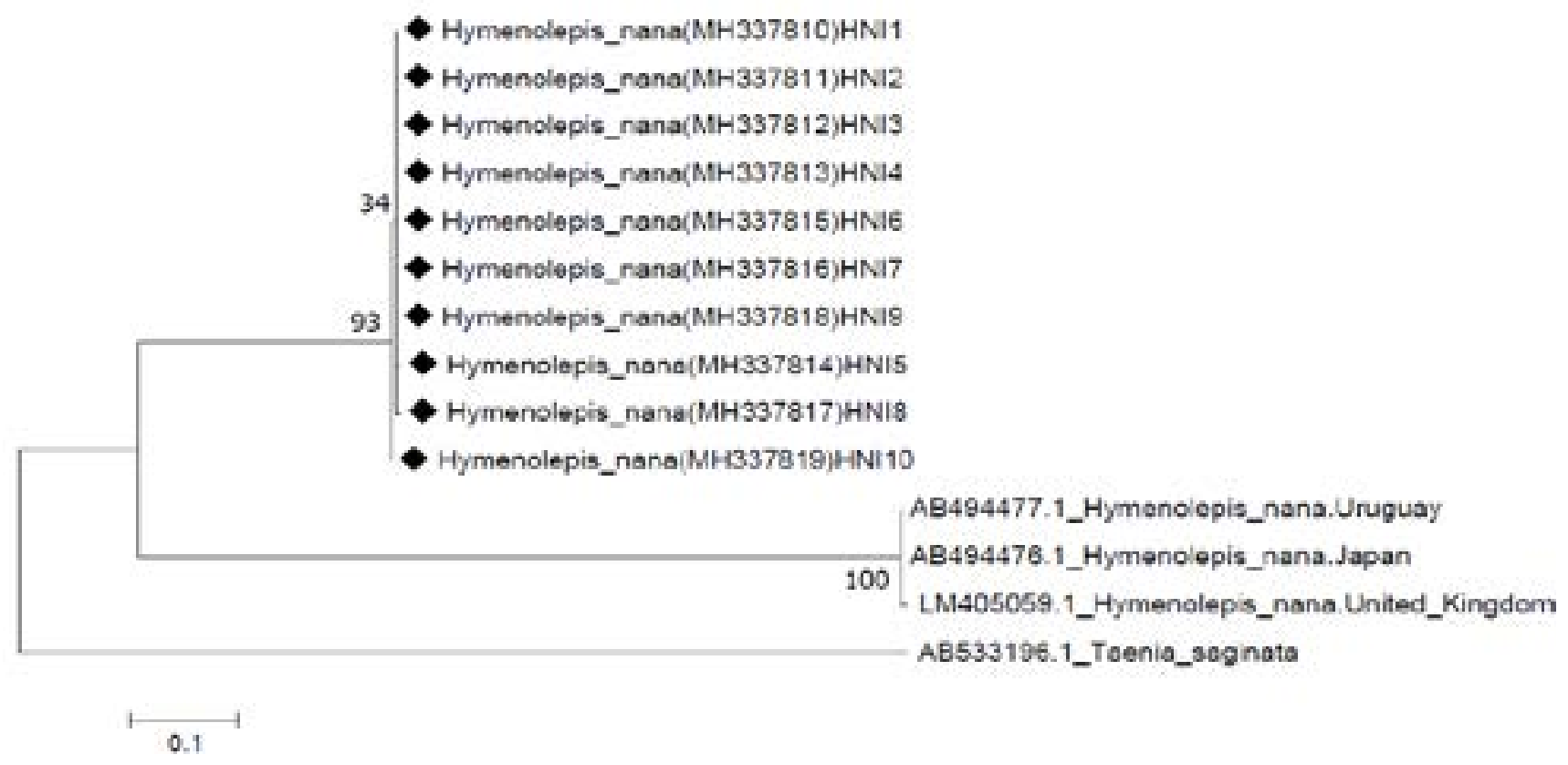

Figure 3: Phylogenetic relationshipsamong H.nana taxainferred by ML methods. The phylogeny inferred from the ML analyses showedidentical tree topologies withstrong bootstrap values. The overall tree structure included two clusters. $H$. nana was clarified in present study $(\bullet)$, a close intra-specific proximity was seen among the isolates of $H$. nanaobtained fromdifferent isolates including the isolates of our study and also the isolates of other countries.

The highest infection rate was observed in the age group under 30 years old. The results of clinical signs showed abdominal pain was the most frequent gastrointestinal symptom in the people infected with $H$. nana who had digestive tract symptoms among those the most common symptom was diarrhea.

The phylogeny inferred from the ML analyses showed identical tree topologies with an informative clading pattern with strong bootstrap (1000 replication) values. The overall tree structure included two clusters, labeled as $H$. nana clades. In these clades, a close intra-specific proximity was seen among the isolates of $H$. nana obtained from different isolates including the isolates of our study and also the isolates of other countries.

\section{Discussion}

Human hymenolepiasis, a disease that occurs throughout the world, is usually produced by two species of Hymenolepis-H. nana and $H$. diminuta ${ }^{3}$. Diagnosis and identification of these tapeworms in human patients is usually based on egg morphology in fecal examination ${ }^{13}$. However, the identification based on morphology has not been a suitable method in determining the species of tapeworm due to the similarities present in the morphological and phenotypic profile of different stages of the parasite eggs $^{23}$. In the current study, we used PCR-sequencing technique for characterization of nuclear rDNA ITS2 gene sequences of $H$. nana to precisely identify the parasite. So far, different studies have been carried out in Iran where $H$. nana infections have been reported. Kheirandish ${ }^{18,19}$ and Badparva et $\mathrm{al}^{20}$ in three different studies conducted to determine the prevalence of intestinal parasites in Western Iran, reported $H$. nana infection rates of $0.1 \%, 0.5 \%$, and $0.3 \%$, respectively ${ }^{18-20}$. Another study in Northern Iran found an infection rate of $1.9 \%$ caused by $H$. nana among the food handlers of Sari, the capital of Mazandaran province ${ }^{24}$. In a study on 800 schoolchildren in Golestan province, northern Iran, H. nana infection rate was $1.5 \%{ }^{25}$. Similarly, in a study performed in rural region of Orumiyeh, northwest of Iran, the infection rate of the parasite in primary school children was $0.2 \%{ }^{22}$. Likewise, in two different studies carried out in southwestern Iran the infection rates by $H$. nana were estimated at $1.29 \%(2012)$ and $0.04 \%(2017)^{26,27}$. Lastly, in a study from Mashhad, northeast Iran, the infection rate caused by $H$. nana among HIV positive individuals (2010) was reported around 10\%. In the current study, the infection rate of $H$. nana parasite was $0.6 \%$ while in a 
previous study conducted in Qazvin province in 2015 it was $0.01 \%{ }^{28}$. This difference in infection rate may be due to reasons such as the difference in sample size, sampling sites, low sensitivity of the diagnostic method, and finally the use of single stool examination method. Infections with $H$. nana in humans are ubiquitous, particularly in children of developing countries ${ }^{29-31}$. In a study reported from Thailand, stool examination was performed on 2083 Thai children from orphanages and primary schools. The worm infection was only found in children from orphanages with a prevalence rate of $13.12 \%{ }^{8}$., Also, the infection rate in children of Ethiopia, Mexico, and Pakistan was detected at $28.3 \%, 1.5 \%$, and $1.8 \%$, respectively ${ }^{32-34}$. It is worth mentioning that $H$. nana is the most common cestode of humans, particularly in young individuals and mainly in children ${ }^{35,36}$. In the present study, the highest infection rate was observed in the age group under 30 years old, a finding consistent with that of a previous study on this parasite $8,32,34,37,38$.

H. nana usually causes many clinical symptoms such as headache, weakness, loss of appetite (anorexia), meteorism (bloating, nausea, vomiting, itching, irritability, sleeplessness, enuresis, abdominal pain, and diarrhea) ${ }^{8}$. In the present study, diarrhea was found as the most common gastrointestinal symptom in the patients, a finding in harmony with several reports of infection in India and Mexico $^{37,38}$.

Since the isolates of $H$. nana infecting humans and rodents are morphologically identical, the only way they can be reliably distinguished is by comparing the parasite in each host using molecular techniques ${ }^{17}$. Genetic diversity of $H$. nana has been studied using some genetic makers, such as cytochrome c oxidase subunit $1(\operatorname{cox} 1)$ and the first and second internal transcribed spacer (ITS-1 and ITS-2) regions of nuclear ribosomal DNA (rDNA) ${ }^{39,40}$.

Furthermore, the utility of rDNA ITS2 in predictingthe secondary structure from the primary sequence data can add ancillary information which could be further used in species identification ${ }^{41}$ as well as in providing resolution at higher taxonomic levels ${ }^{42,43}$. These studies have indicated the existence of genetic variation of $H$. nana from different domestic and wildlife host species in different areas, suggesting that $H$. nana is a species complex, or "cryptic" species (morphologically identical but genetically distinct). In a study, the sequences of internal transcribed spacer 2 (ITS2) region of ribosomal DNA and a partial sequences of the mitochondrial cytochrome $\mathrm{c}$ oxidase subunit 1 gene were compared between an isolate of $H$. nana, collected from a laboratory mouse (Mus musculus) from Japan, and a laboratory golden hamster (Mesocricetus auratus) from Uruguay. No sequence differences in the ITS2 were found between both isolates ${ }^{39}$. In the current study, all ten positive specimens of $H$. nana successfully multiplied by molecular method and no sequence differences were found in the ITS2 between the isolates.

\section{Conclusion}

The PCR-sequencing technique used in the current study successfully and accurately identified all isolates. Thus, this technique could offer a valuable diagnostic tool when human eggs are the only source available to identify and diagnose $H$. nana parasite.

\section{Acknowledgments}

The authors are grateful to the laboratory staff of Shahid Bolandian Helath Care Center of Qazvin. We would like to appreciate the assistance offered by the colleagues at Department of Parasitology and Mycology, Medical School, Qazvin University of Medical Sciences.

\section{Conflict of interest}

We declare no conflict of interest.

\section{References}

1. Cheng T, Liu GH, Song HQ, Lin RQ, Zhu XQ. The complete mitochondrial genome of the dwarf tapeworm Hymenolepis nana-a neglected zoonotic helminth. Parasitology Research. 2016; 115(3): 1253-62.

2. Sharma S, Lyngdoh D, Roy B, Tandon V. Differential diagnosis and molecular characterization of Hymenolepis nana and Hymenolepis diminuta (Cestoda: Cyclophyllidea: Hymenolepididae) based on nuclear rDNA ITS2 gene marker. Parasitology research. 2016; 115(11): 4293-8.

3. Thompson RA. Neglected zoonotic helminths: Hymenolepis nana, Echinococcus canadensis and Ancylostoma ceylanicum. Clinical Microbiology and Infection. 2015; 21(5): 426-32.

4. Liao CW, Fu CJ, Kao CY, Lee YL, Chen PC, Chuang TW, Naito T, Chou CM, Huang YC, Bonfim I, Fan CK. Prevalence of intestinal parasitic infections among school children in capital areas of the Democratic Republic of São Tomé and Príncipe, West Africa. African health sciences. 2016; 16(3): 690-7.

5. Haq KU, Gul NA, Hammad HM, Bibi Y, Bibi A, 
Mohsan J. Prevalence of Giardia intestinalis and Hymenolepis nana in Afghan refugee population of Mianwali district, Pakistan. African health sciences. 2015; 15(2): 394400.

6. Craig P, Ito A. Intestinal cestodes. Current opinion in infectious diseases. 2007; 20(5): 524-32.

7. Schantz PM. Tapeworms (cestodiasis). Gastroenterology Clinics of North America. 1996; 25(3): 637-53.

8. Sirivichayakul C, Radomyos PR, Praevanit R, Jojjaroen-Anant $\mathrm{C}$, Wisetsing P. Hymenolepis nana infection in Thai children. Journal Medical Association of Thailand. 2000; 83(9): 1035-8.

9. Gupta S, Katiyar JC. Comparative activity of anticestode drugs - praziquantel, niclosamide and Compound 77-6, against Hymenolepis nana. Journal of helminthology. 1983; 57(1): 31-6.

10. Beaver PC, Jung RC, Cupp EW, Craig CF. Clinical parasitology. Philadelphia: Lea \& Febiger. 1984.

11. Mirdha BR, Samantray JC. Hymenolepis nana: a common cause of paediatric diarrhoea in urban slum dwellers in India. Journal of Tropical Pediatrics. 2002; 48(6): 331-4.

12. Smyth JD, McManus DP. The physiology and biochemistry of cestodes. Cambridge University Press, 2007. 13. Nkouawa A, Haukisalmi V, Li T, Nakao M, Lavikainen A, Chen X, Henttonen H, Ito A. Cryptic diversity in hymenolepidid tapeworms infecting humans. Parasitology International. 2016; 65(2): 83-6.

14. Mahami-Oskouei M, Dalimi A, Forouzandeh-Moghadam M, Rokni MB. Molecular identification and differentiation of Fasciola isolates using PCR-RFLP method based on internal transcribed spacer (ITS1, 5.8 S rDNA, ITS2). Iranian Journal of Parasitology. 2011; 6(3): 35.

15. Rokni MB, Mirhendi H, Mizani A, Mohebali M, Sharbatkhori M, Kia EB, Abdoli H, Izadi S. Identification and differentiation of Fasciola hepatica and Fasciola gigantica using a simple PCR-restriction enzyme method. Experimental parasitology. 2010; 124(2): 209-13.

16. Sharma S, Lyngdoh D, Roy B, Tandon V. Differential diagnosis and molecular characterization of Hymenolepis nana and Hymenolepis diminuta (Cestoda: Cyclophyllidea: Hymenolepididae) based on nuclear rDNA ITS2 gene marker. Parasitology Research. 2016; 115(11): 4293-8.

17. Cheng T, Gao DZ, Zhu WN, Fang SF, Chen N, Zhu XQ, Liu GH, Lin RQ. Genetic variability among Hymenolepis nana isolates from different geographical regions in China revealed by sequence analysis of three mitochondrial genes. Mitochondrial DNA Part A. 2016; 27(6): 4646-50.
18. Kheirandish F, Tarahi MJ, Haghighi A, Nazemalhosseini-Mojarad E, Kheirandish M.Prevalence of intestinal parasites in bakery workers in Khorramabad, Lorestan Iran. Iranian Journal of Parasitology. 2011; 6(4): 76.

19. Kheirandish F, Tarahi MJ, Ezatpour B. Prevalence of intestinal parasites among food handlers in Western Iran. Revista do Instituto de Medicina Tropical de São Paulo. 2014; 56(2): 111-4.

20. Badparva E, Kheirandish F, Ebrahimzade F. Prevalence of intestinal parasites in Lorestan Province, West of Iran. Asian Pacific Journal of Tropical Disease. 2014; 4: 728-32.

21. Berenji F, Sarvghad MR, Fata A, Hosseininejad Z, Saremi E, Ganjbakhsh M, Izadi Jahanparvar R. A study of the prevalence of intestinal parasitic infection in HIV positive individuals in Mashhad, Northeast Iran. Jundishapur Journal of Microbiology. 2010; 3(2): 61-5.

22. Tappe KH, Mohammadzadeh H, Khashaveh S, Rezapour B, Barazesh A. Prevalence of intestinal parasitic infections among primary school attending students in Barandooz-Chay rural region of Urmia, West Azerbaijan province, Iran in 2008. African Journal of Microbiology Research. 2011; 5(7): 788-91.

23. Yamasaki H, Nakaya K, Nakao M, Sako Y, Ito A. Significance of molecular diagnosis using histopathological specimens in cestode zoonoses. Tropical Medicine and Health. 2007; 35(4): 307-21.

24. Sharif M, Daryani A, Kia E, Rezaei F, Nasiri M, Nasrolahei M. Prevalence of intestinal parasites among food handlers of Sari, Northern Iran. Revista do Instituto de Medicina Tropical de São Paulo. 2015; 57(2): 139-44.

25. Rostami M, Tohidi F, Sharbatkhori M, Taherkhani H. Intestinal parasitic infection among school children in Golestan province. Iran. Pak J Biol Sci. 2012; 15(23): 1191125. PubMed.

26. Saki J, Khademvatan S, Masoumi K, Chafghani M. Prevalence of intestinal parasitic infections among food handlers in Khuzestan, Southwest of Iran: a 10-year retrospective study. African Journal of Microbiology Research. 2012; 6(10): 2475-80.

27. Saki J, Khademvatan S, Foroutan-Rad M, Gharibzadeh M. Prevalence of intestinal parasitic infections in Haftkel County, southwest of Iran. International Journal of Infection. 2017; 4(4).

28. Sadeghi H, Bakht M, Saghafi H, Shahsavari T. Prevalence of intestinal parasites in a population in Eghbalieh city from Qazvin Province, Iran. Journal of Parasitic Diseases. 2015; 39(2): 126-9. 
29. Khanal LK, Choudhury DR, Rai SK, Sapkota J, Barakoti A, Amatya R, Hada S. Prevalence of intestinal worm infestations among school children in Kathmandu, Nepal. Nepal Med Coll J. 2011; 13(4): 272-4.

30. Matthys B, Bobieva M, Karimova G, Mengliboeva Z, Jean-Richard V, Hoimnazarova M, Kurbonova M, Lohourignon LK, Utzinger J, Wyss K. Prevalence and risk factors of helminths and intestinal protozoa infections among children from primary schools in western Tajikistan. Parasites \& vectors. 2011; 4(1): 195.

31. Abera B, Alem G, Yimer M, Herrador Z. Epidemiology of soil-transmitted helminths, Schistosoma mansoni, and haematocrit values among schoolchildren in Ethiopia. The Journal of Infection in Developing Countries. 2013; 7(03): 253-60.

32.Amare B, Ali J, Moges B, Yismaw G, Belyhun Y, Gebretsadik $S$, Woldeyohannes D, Tafess $\mathrm{K}$, Abate E, Endris M, Tegabu D. Nutritional status, intestinal parasite infection and allergy among school children in Northwest Ethiopia. BMC Pediatrics. 2013; 13(1): 7.

33. Tasawar Z, Gul S, Bhutta MA, Arif M. Prevalence of hymenolepis nana in human beings in and around Multan-Pakistan. Pak J Life Soc Sci. 2004 ;2(1): 62-4.

34. Morales EM, Sánchez HJ, García MD, Vargas G, Méndez JD, Pérez M. Intestinal parasites in children, in highly deprived areas in the border region of Chiapas, Mexico. Salud pública de méxico. 2003; 45(5).

35. Acha PN, Szyfres B. Zoonoses and communicable diseases common to man and animals. Pan American Health Org; 2003.
36. Craig P, Ito A. Intestinal cestodes. Current Opinion in Infectious Diseases. 2007; 20(5): 524-32.

37. Mirdha BR, Samantray JC. Hymenolepis nana: a common cause of paediatric diarrhoea in urban slum dwellers in India. Journal of Tropical Pediatrics. 2002; 48: 331-334.

38. Martínez-Barbabosa I, Cárdenas ME, Gaona E, Shea M. The prevalence of Hymenolepis nana in schoolchildren in a bicultural community. Revista Biomédica. 2010; 21(1): 21-7.

39. Okamoto M, Agatsuma T, Kurosawa T, Ito A. Phylogenetic relationships of three hymenolepidid species inferred from nuclear ribosomal and mitochondrial DNA sequences. Parasitology. 1997; 115(6): 661-6.

40. Macnish MG, Morgan-Ryan UM, Monis PT, Behnke JM, Thompson RC. A molecular phylogeny of nuclear and mitochondrial sequences in Hymenolepis nana (Cestoda) supports the existence of a cryptic species. Parasitology. 2002; 125(6): 567-75.

41. Coleman AW. Pan-eukaryote ITS2 homologies revealed by RNA secondary structure. Nucleic Acids Research. 2007; 35(10): 3322-9.

42. Ghatani S, Shylla JA, Tandon V, Chatterjee A, Roy B. Molecular characterization of pouched amphistome parasites (Trematoda: Gastrothylacidae) using ribosomal ITS2 sequence and secondary structures. Journal of Helminthology. 2012; 86(1): 117-24.

43. Schultz J, Maisel S, Gerlach D, Müller T, Wolf M. A common core of secondary structure of the internal transcribed spacer 2 (ITS2) throughout the Eukaryota. Rna. 2005; 11(4): 361-4. 